\title{
New Experience in Reducing Harmful Emissions in the Exhaust Gases of Marine Diesels
}

\author{
Anatoliy Danylyan', Igor Maslov', Nataliia Tiron-Vorobiova ${ }^{1 *}$, Olha Romanovska ${ }^{1 *}$ \\ 1 Danube Institute of National University "Odessa Maritime Academy" (NU "OMA"), Odessa Region, \\ Fanagoriiska 9, Izmail, 68607, Ukraine \\ * Corresponding author's e-mail: enginmarin@ukr.net
}

\begin{abstract}
The scientific article deals with new directions in reducing the harmful emissions in the exhaust gases of marine engines. For the first time in the world shipping practice, a scientific and production company "Eco-Auto-Titan" Ukraine used a fuel oil filter catalyst (FOFC) on the vessels of the "Ukrainian Danube Shipping Company" (the PJSC "UDP") All research work was carried out by the Danube Institute NU "OMA" with the monitoring and confirmation of the results by Institute for Environment and Energy Conservation (Kyiv).
\end{abstract}

Keywords: fuel oil filter catalyst, company "Eco-Auto-Titan"

\section{INTRODUCTION}

The rapid growth of world industry and transport has dramatically aggravated the state of ecology and the human environment. The World Health Organization (WHO), monitors annually and analyzes the content of harmful inclusions in the air of our planet. The results of the research on the main indicators of harmful emissions exceed the maximum permissible standards tens or hundreds of times, negatively impacting the health and life expectancy of all mankind.

Out of the total amount of emissions into the atmosphere, the world marine and river fleet emits about $15 \%$ of all emissions from the exhaust gases of marine diesel engines. Taking into account that the river fleet of European countries operates on the inland waterways along the coast of densely populated areas, the relevance of reducing the concentration of harmful emissions in the exhaust gases of marine internal combustion engines becomes obvious.

The article deals with a new, efficient and cheaper method for purification of the exhaust gases from marine engines is proposed. This method is the most accessible for use on inland river vessels, as it is implemented on the basis of modern processing of diesel fuel by nanotechnologies without traditional traps of harmful emissions on the line of exhaust gas from diesel engines. The existing methods for treating harmful emissions from the line of the exhaust gases from the marine diesel engines are outdated and do not provide adequate treatment that meets the modern requirements.

Danube Institute of National University "Odessa Maritime Academy" (NU "OMA"), together with the scientific-production company "Eco-Auto-Titan" - Ukraine, carries out the research work on river vessels of the National carrier of the PJSC on the introduction of the FOFC, developed by "Eco-Auto-Titan" and is being introduced for the first time in world practice on transport vessels of the river and sea fleet of Ukraine.

In the countries of the European Union, the harmful emissions of substances in the exhaust gases of diesel engines are standardized in accordance with the rules of the UN Economic Commission for Europe No. 49, which are based on the requirements of the 1958 Geneva Agreement. Over the past years, these rules have undergone major changes to meet stricter pollution standards for emissions of harmful substances into the atmosphere. According to the modern requirements 
of the Euro-5 standard, emissions of harmful substances in the exhaust gases of marine mediumspeed diesel engines are reduced by 2.5 times due to nitrogen oxide $\mathrm{NO}_{\mathrm{x}}$ to $2 \mathrm{~g} / \mathrm{kWh}$. Carbon monoxide $\mathrm{CO}$ and hydrocarbon $\mathrm{CH}$, are reduced by 1.4 times. The soot emissions in the exhaust gases of the marine internal combustion engines are tightened 5 times.

According to the requirements of the MARPOL 73/78 International Convention for the Prevention of Pollution from Ships, for the ships the keel of which was laid in 2016, all the above mentioned standards were tightened, except for sulfur oxide $\mathrm{SO}_{x}$, the sulfur standard $\mathrm{S}, 0.10 \%$ in diesel fuel for sailing in special areas of the World Ocean was set for all vessels excluding the year of build. At this rate of sulfur in the fuel, the $\mathrm{SO}_{\mathrm{x}}$ emissions should be no more than $4.5 \mathrm{~g} / \mathrm{kWh}$ (MARPOL 73/78 2018).

In October 2017, by the decision of the Paris Conference, the carbon dioxide $\mathrm{CO}_{2}$ indicator was introduced as a harmful inclusion in the exhaust gases of internal combustion engines and industrial emissions. The requirements for meeting the standards pertaining to reducing $\mathrm{CO}_{2}$ for marine vessels are determined by the energy efficiency coefficient of the energy efficiency index - Energy Efficiency Design Index (EEDI) (Danylyan et al. 2017).

The new methods and technologies used for treating the harmful pollutants in the exhaust gases of marine engines by catalytic type catalysts installed at the outlet of the exhaust gas engine for several reasons are outdated due to the tightening requirements for the exhaust gases of marine diesel engines and sharply increasing prices for the production of catalysts. The use of biofuels, water-fuel emulsions (WFE), gas fuels, changing the phases of engine operation, exhaust gas regeneration; all this has its further development in the purification of the exhaust gases of marine internal combustion engines of the exhaust gas engine.

Danube institute NU "OMA" together with the research-and-production company "EcoAuto-Titan" Ukraine on the vessels of the PJSC "UDP" over the past three years has been conducting the research on the river vessels of the PJSC "UDP" of the FOFC 14 DM Fuel Well in order to determine the reduction of harmful indicators in the exhaust gases of the shipboard internal combustion engines of the engine and the fuel economy.
For the first time in the world practice, the use of FOFC 14 DM Fuel Well on ships of the PJSC "UDP", has opened a new direction in the processing of diesel fuel using nanotechnology to reduce the harmful emissions in the exhaust gas engine, which will drastically decrease the cost of operating ships for the transport of goods and will allow Ukrainian ships to work in the inland waters of the European Union in accordance with modern environmental requirements.

\section{MATERIAL AND METHODS}

The first research on the Fuel Well FOFC catalyst was conducted on the Danube river in the port of Ismail on tug "Portovy-22" of the PJSC "UDP", 2016. Further tests were carried out in 2017 on the ship "Kapitan Zhidkov" and in 2018 on the ship "Mechanic Senilov" of the PJSC "UDP". These were two similar dry cargo vessels with the ability to push non-self-propelled units. The power plant of each vessel is $1,500 \mathrm{~kW}$ with the ability to transport goods weighing up to 12 thousand tons. The experiment on these ships required the improvement of the fuel catalyst in connection with its use on high-power engines. The research team included such representatives as: the PJSC "UDP", scientific-research company "Eco-Auto-Titan" - Ukraine, Danube institute NU "OMA" (authors of the article), scientists of Institute for Environment and Energy Conservation (Kyiv).

Before starting the research, Danube institute NU "OMA" prepared a testing program for the FOFC and a scheme of its connection to the ship fuel system, which ensured high-quality data processing in all test modes.

The developed catalyst connection system enabled to switch from the work with catalyst to the work without it with a minimal loss of time, which significantly affected the fairness of the experiment. It was especially important at each mode to compare the data, fixing the actions of the catalyst.

The connection of a special measured tank enabled, with a high degree of accuracy, to determine the fuel economy, which amounted to $3.0 \%$, taking into account the operation of the catalyst. The catalyst itself is a nanotechnology design that has been certified by the State Standard and the Marine and River Shipping Register of Ukraine. 
In order to control the harmful atmospheric emissions in the exhaust gas of the main marine engines, the following instruments were used: - ship gas analyzer - Testo-350; - portable smoke meter device - IDP-2; - electronic indicator of the control of work processes of internal combustion engines - Lautert-50; - Siemens flow meters of fuel and air. Each device meets all modern requirements of performance management and is certified by the international state authority.

The measurements of all engine performance indicators were performed in accordance with the requirements of IMO 73/78.

Installation of devices for measuring indicators was carried out in accordance with the requirements of MARPOL 73/78. A probe for sampling (gas analysis) was installed on the exhaust manifold of the internal combustion engine at a distance of at least six diameters of the collector from the flange attached to the engine. The probe of the sampling device was lowered along the axis of the exhaust gas flow of the engine to a depth of 500-1000 mm inside the exhaust manifold. Sampling (required probe sections) was carried out using the Testo-350 gas analyzer to indicate the components of the chemical composition of the exhaust gases. All requirements specified in the passport of the device must be fulfilled. A flow meter was installed to control the incoming air into the engine providing high-quality combustion of fuel in the internal combustion engine cylinder.

The concentration of harmful emissions in the exhaust gas was measured according to the developed testing program for steady state engine operation. Control was carried out at the following loads: $0.25,0.5,0.75,1.0$ of the worked-out capacity. The measurement frequency of all indicators in each load mode of the internal combustion engine was performed three times with an interval of one minute, the permissible error of measurements should not differ more than $10 \%$ from each measurement. Along with measurements by a portable smoke meter device and a gas analyzer, the indirect and direct parameters of the internal combustion engine operation were controlled:

- fuel consumption;

- engine speed;

- the temperature of the exhaust gases in the cylinders;

- cooling temperature of the inner profile;

- temperature of the circulating (lubricating) oil.
The power developed by each cylinder of the internal combustion engine with an electronic device was determined with a high degree of accuracy (TFK Test Program 2018).

On September 2, 2019, a proposal from our partner "Eco-Auto-Titan" to test the fuel catalyst on an average marine seiner in the area of fishing off the West Indian Ocean and in the waters of the Arabian Sea was received. The authors of the article developed a testing program that determined the main ways and methods of research.

The customer set the task to determine the real fuel economy for the entire period of the voyage and the percentage reduction in black carbon (soot) in the exhaust gases of the marine main engine using a fuel catalyst. The results of the research showed $17.5 \%$ fuel economy, the reduction of soot emissions in the exhaust gases was stable, kept at level $50-60 \%$, the temperature of the exhaust gases dropped to $30^{\circ} \mathrm{C}$ (Conformity test certificate 2019).

Unfortunately, at present, the region of the Indian Ocean and the Arabian Sea does not meet the requirements of MARPOL 73/78 on the emission of $\mathrm{NO}_{\mathrm{x}}$ - nitrogen oxide, $\mathrm{CO}_{\mathrm{x}}$ - carbon monoxide and other indicators, which did not allow a complete gas analysis of the harmful emissions in the exhaust gases from a marine diesel.

There is a special method for calculating the harmful emissions in the exhaust gas, which allows double-checking the data obtained by the gas analyzer. During the experiment, a number of indicators were rechecked, which made it possible to verify the correctness of the readings of the devices.

\section{The methodology for calculating individual indicators of the harmful emissions in the exhaust gas of an internal combustion engine}

Soot concentration means its mass fraction in the dry exhaust gases; it is determined by the reading of a portable smoke meter device, or by conversion to the optical density of the exhaust gases. The optical density of the exhaust gas is determined in \% (Fig. 1) [Guidelines for the calculation of emissions of pollutants into the atmosphere 1987].

In order to convert the carbon black content of soot to mass unit, the working formula was used:

$$
\begin{gathered}
C_{c}=1,262 \cdot 10^{-4} \cdot \kappa^{2}-1,98 \cdot \\
10^{-3} \cdot \kappa+3,67 \cdot 10^{-2} \mathrm{gr} / \mathrm{m}^{3}
\end{gathered}
$$


where: $C_{c}-$ the content of dispersed carbon in the exhaust gas;

$\kappa-$ is the light attenuation coefficient according to the passport of a measurer smoke portable device.

At a carbon monoxide concentration, the volume or mass fraction of $\mathrm{CO}$ in the dry exhaust gas is understood. Concentration was recalculated according to the formula:

$$
C_{C O} \mathrm{gr} / \mathrm{m}^{3}=12,5 \cdot C_{C O} \% \text { of the volume }
$$

Nitrogen oxides correspond to a mixture of various nitrogen oxides except nitrogen oxide $\mathrm{N}_{2} \mathrm{O}$ formed in the cylinder during fuel combustion.

Under the concentrations of nitrogen oxides volume or mass fraction in the dry exhaust gas of nitrogen dioxide $\mathrm{NO}_{2}$ under the assumption that all oxides of the $\mathrm{NO}_{\mathrm{x}}$ type are converted into an equivalent amount of $\mathrm{NO}_{2}$. Concentration is calculated according to the formula:

$$
C_{\mathrm{NO} 2} \mathrm{gr} / \mathrm{m}^{3}=20,5 \cdot C_{\mathrm{NO} 2} \% \text { of the volume }
$$

The conversion of volumetric units into millionths of the content of harmful emissions in the exhaust gases, according to the gas analyzer in ppm Testo-350, is carried out by calculation from the convector units.

All readings of the gas analyzer were determined by it in ppm; if it was necessary to obtain data on the content of harmful emissions in $\mathrm{g} / \mathrm{kWh}$, then a recount was carried out using a convector.
International requirements according to MARPOL 73/78 of January 01, 2016 take into account the engine speed, i.e. the higher the speed, the more stringent the requirements for harmful emissions in the exhaust gases.

\section{Processing the results}

The specific emission of nitrogen oxides $l_{N O x}$ and carbon monoxide $l_{C O}$ was determined by the formulas:

$$
\begin{aligned}
& l_{\text {NOX }}=\frac{5,72 \cdot 10^{4} \cdot \mathrm{C}_{\text {NOX }} \cdot\left(G_{\text {air }}-0,000974 \cdot G_{f}\right)}{N_{i}} \\
& l_{C O}=\frac{3,48 \cdot 10^{4} \cdot \mathrm{C}_{\mathrm{CO}} \cdot\left(G_{\text {air }}-0,000974 \cdot G_{f}\right)}{N_{i}}
\end{aligned}
$$

where: $C_{N O \mathrm{x}}$ and $C_{C O}-$ concentration of nitrogen oxides and carbon monoxide, $\%$;

Gair - air consumption, kg/s;

$G f$ - fuel consumption, $\mathrm{g} / \mathrm{s}$;

$\mathrm{Ni}$ - effective diesel power in test mode, $\mathrm{kW}$.

Air consumption was determined by the formula:

$$
G_{\text {air }}=\frac{\alpha_{\Sigma} \cdot L_{m} \cdot G_{f} \cdot 28,95}{3600} \mathrm{~kg} / \mathrm{s}
$$

where: $\alpha_{\Sigma}-$ the total coefficient of excess air;

$G_{f}$ - fuel consumption, $\mathrm{kg} /$ hour;

$L_{m}-$ the theoretical amount of air required for combustion of $1 \mathrm{~kg}$ of fuel used composition, $\mathrm{mol} / \mathrm{kg}$.

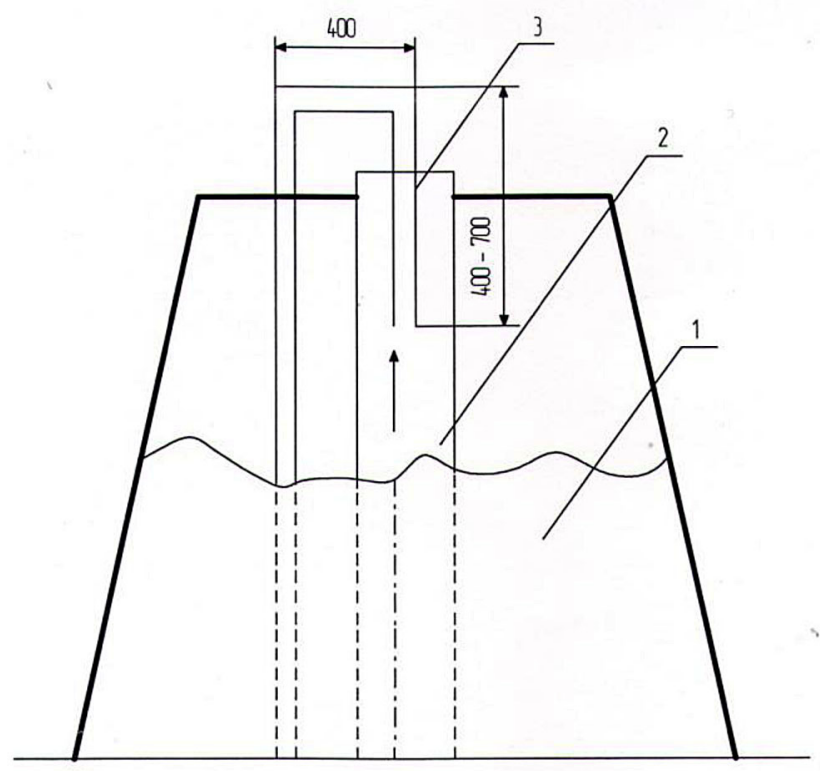

Fig. 1. Exhaust pipe of the test engine: 1 - casing of the exhaust pipe of the main engine, 2 -exhaust pipe of the main engine, 3 - place of sampling of the exhaust gases of main engine 
For fuel composition $\mathrm{C}=66 \% ; \mathrm{H}=13 \%$; $\mathrm{O}=1 \% . \mathrm{Lt}=0.495 \mathrm{~mol} / \mathrm{kg}$.

When analyzing the composition of the exhaust gases, the value was determined by the formula:

$$
\alpha_{\Sigma}=\frac{1}{1-3,76 \cdot 0_{2} / N_{2}}
$$

The nitrogen content in the combustion products was calculated by the formula:

$$
\mathrm{N}_{2}=100-\left(\mathrm{CO}_{2}+\mathrm{O}_{2}\right)
$$

where: $\mathrm{N}_{2}, \mathrm{CO}_{2}, \mathrm{O}_{2}-$ content in the products of combustion of nitrogen of carbon dioxide and oxygen as a percentage by volume.

When calculating the accepted specific emissions of harmful substances, the value of $\alpha_{\Sigma}$ was determined by the formula:

$$
\alpha_{\Sigma}=\alpha \cdot \frac{\alpha_{1}}{\eta_{H}}
$$

where: $\alpha$ - coefficient of excess air during fuel combustion $\alpha=1.8-2.0$;

$\alpha_{1}-$ the coefficient of excess purge air, $\alpha_{1}=1.05-1.15$ for 4-stroke diesels.

$\alpha_{1}=1.8-1.4$ for 2-stroke diesels;

$\eta_{H}$ - cylinder filling ratio,

$\eta_{H}=0.8-0.9$ for 4-stroke diesels, $\eta_{H}=0.7-0.9$ for 2-stroke diesels (lower values for naturally aspirated diesel engines).
The conditional exhaust gas flow rate was determined by the formulas:

- for 4 stroke diesels

$$
V_{H}=\frac{V_{n} \cdot n}{120}
$$

- for 2 stroke diesels

$$
V_{H}=\frac{V_{n} \cdot n}{60}
$$

where: $V_{H}$ - the total working volume of the diesel cylinders, $\mathrm{dm}^{3}$;

$n$ - the rotation speed of the crankshaft of the diesel engine, $\mathrm{m}^{-1}$.

\section{RESULTS AND DISCUSSION}

Before starting the tests, the authors developed a testing program that was supplemented and modified taking into account each tested vessel and its main engine. The connection scheme of the FOFC enabled to quickly switch the engine from work with catalyst to its normal operation without it. The use of fuel flow meters and an integrated measuring tank in the scheme enabled to determine the fuel consumption with high accuracy. The control of the fuel combustion process was controlled by an electronic modern device from Lautert DP-50.

All tests were carried out with the direct participation of scientists from Institute for Environment and Energy Conservation (Kyiv) with

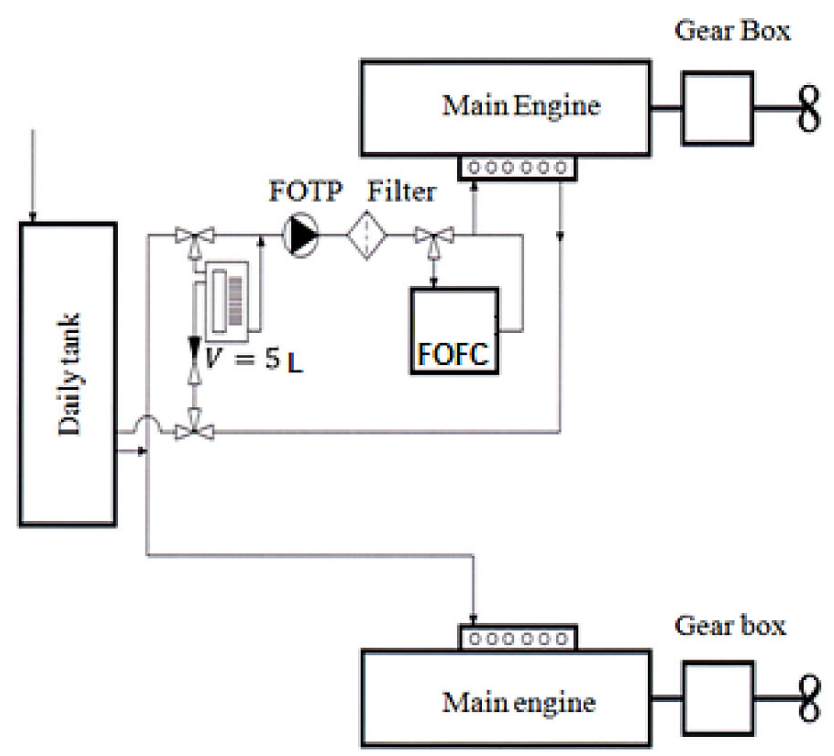

Fig. 2. Scheme of connecting the fuel catalyst in the ship system of the main engine. FOFC; FOTR - fuel oil transfer pump, $V=5 \mathrm{dm}^{3}$ - Measuring tank to control fuel economy 


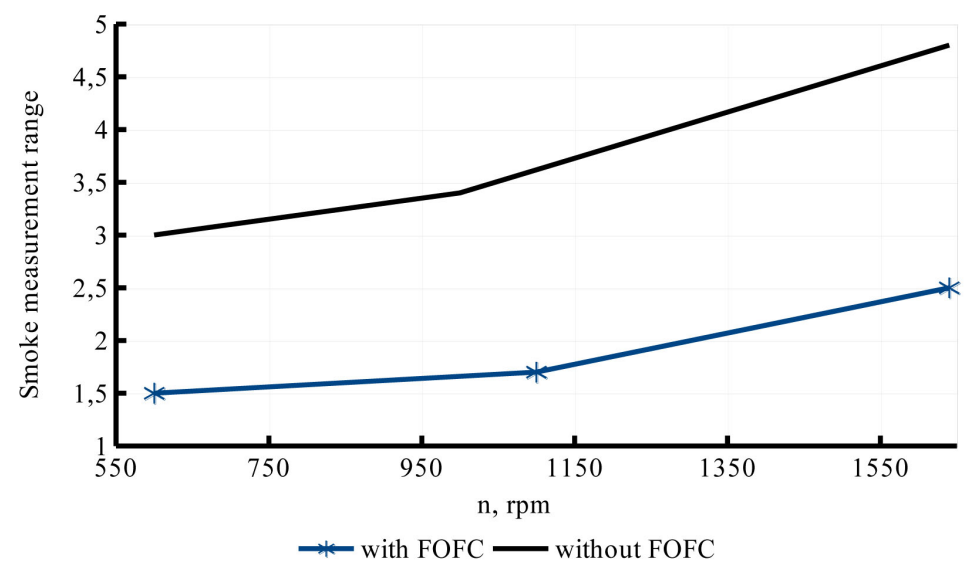

Fig. 3. Smoke ratio diagram taken with IDP-2, smoke gauge from BA-6M-816 Deutz engine, $\mathrm{Ne}=250 \mathrm{~kW}, n_{\max }-1800$ revolution per minute $-\mathrm{rpm}$, (motor vessel) - m/v "Portovy-22" (Materials of the meeting of the International Danube Commission on the implementation TFK 2016). Smoke level determined using IDP-2 portable smoke meter device Deutz engine: $1(10 \%), 2(20 \%), 3(30 \%), 4(40 \%), 5(50 \%), 6$ (60\%) - axic "y" (smoke measurement range)

international certification of such studies. The tests carried out were confirmed by detailed scientific material from the above mentioned institute.

It must be admitted that the collected test material has its positive and negative sides, which are currently being studied by DI NU "OMA". Low fuel economy has become a stumbling block, and this figure for shipowners of Ukraine today, unfortunately, is more significant than the environmental performance of the vessel.

By calculating using the "Diesel - RK" program, which allows simulating the operation of the engine under test, the possible limits of the localization of harmful emissions in the exhaust gases of marine diesel engines were found. Unfortunately, with respect to nitrogen oxide $\mathrm{NO}_{x}$, a more significant decrease was expected, which on two river vessels with sufficiently powerful engines of $760 \mathrm{~kW}$ each, the decrease was $22 \%$ (Fig. 4) and the fuel economy was at the level of the calculated error (Test report on the "Kapitan Zhidkov" ship 2017).

Deep analysis of the test materials of these two vessels showed that the technical condition of marine engines does not meet their technical requirements; these vessels have been in operation for more than 30 years without timely scheduled repairs. The indicator diagrams of engine operation showed a decrease and deregulation of its operation indicators. The parameters characterizing the processes of fuel combustion in the engine cylinder are as follows: $P_{z}$ is the maximum combustion pressure, $P_{c}$ is the maximum compression pressure in the cylinder, $P_{i}$ is the average indicator pressure of the cycle, $T_{o z}$ is the temperature of the exhaust gases. The pressure of fuel injection into the combustion chamber of the engine was significantly reduced, which worsened the dispersion of the atomized fuel and increased its range. All these violations in the technical operation of engines affected the results of the research on the operation of the catalyst fuel filter (Test report on the ship "Kapitan Zhidkov" 2017, Test report on the ship "Mechanic Senilov" 2018).

At the same time, significant results were achieved, despite the above-mentioned disadvantages of the technical condition of the engines. Black carbon (soot) in the exhaust gases was steadily reduced by $50 \%$ in all engines (Fig. 3), and carbon monoxide $\mathrm{CO}$ was reduced by half (Fig. 4).

The tests taking place off the coast of India on marine medium-sized seiners with engines with a power of $N_{e}=250 \mathrm{~kW}$ and engine speeds $n=1800 \mathrm{rpm}$ currently give encouraging results. On the first test engine, fuel economy was $17.5 \%$, soot in the exhaust gases was reduced by $60 \%$, and gas temperature was reduced by $30^{\circ} \mathrm{C}$. Tests are ongoing rpm without Gear Box (Report on the research work on the implementation of TFK 2018).

The result of the smoke measurement is indicated as the coefficient of attenuation of the luminous flux $(N, \%)$ or the natural indicator of attenuation of the luminous flux $\left(K, \mathrm{M}^{-1}\right)$, reduced to the normalised values of the photometric base $(0.43 \mathrm{~m})$ and the temperature of the analysed gas (373 K). 

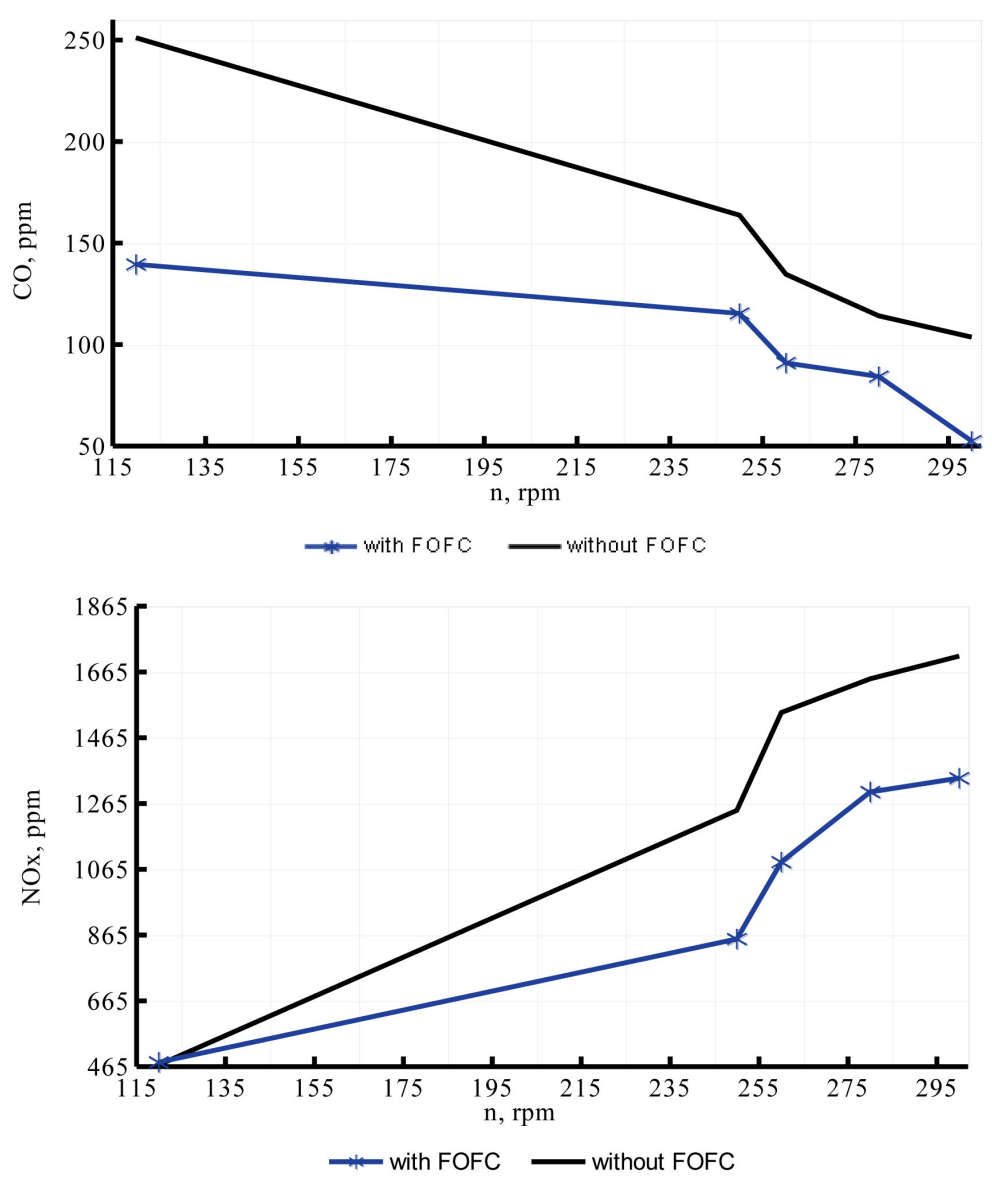

Fig. 4. $\mathrm{CO}$ and $\mathrm{NO}_{\mathrm{x}}$ emission control on $\mathrm{m} / \mathrm{v}$ "Kapitan Zhidkov"

Smoke Measurement Range:

- by the coefficient of attenuation of the luminous flux $(N, \%)$ - from 0 to 100 ;

- by the natural coefficient of attenuation of luminous flux $\left(K, \mathrm{M}^{-1}\right)$ - from 0 to 99 (Fig. 3).

Given the interest of Indian shipowners, the authors, together with the research-and-production company "Eco-Auto-Titan", are negotiating the full-scale testing of an international certified company on a number of fishing vessels in order to obtain the research material for further work.

Considering the latest research areas in the field of reducing harmful emissions in the products of combustion of hydrocarbon fuels, the authors settled on the L.A. Yutkin's effect, which provides new opportunities in reducing harmful emissions in the exhaust gases of internal combustion engines. Creating an electromagnetic field of high tension, allows finding optimal solutions in the absorption of harmful impurities in the exhaust gases of engines. In this regard, a high-voltage source (transformer), model CX-1000 A with a regulated DC voltage in the range of $1 \mathrm{kV}-20$ $\mathrm{kV}$, with a maximum power of $1000 \mathrm{~W}$ will be used (Danylyan 2019). The research work will be carried out on a marine diesel engine with full exhaust gas analysis.

\section{CONCLUSIONS}

The article deals with specific studies of DI NU "OMA" in conjunction with the researchand-production company "Eco-Auto-Titan" on the vessels of the PJSC "UDP" for three years and the Indian Fishing Company in the last months of the current year.

The applied FOFC as a result of research showed positive results in reducing the harmful emissions in the exhaust gases of marine diesel engines:

- $\mathrm{NO}_{\mathrm{x}}$ to $22.0 \%$;

- CO to 50.0-60.0\%;

- solid particles (soot) in the exhaust gases to $50.0 \%$.

- Fuel economy on fishing vessels was $17.5 \%$.

The continuation of research provides for the additional use of an electromagnetic field of high 
tension to further reduce nitrogen oxide $\mathrm{NO}_{\mathrm{x}}$, as well as conduct the experiments to reduce carbon dioxide $\mathrm{CO}_{2}$ in the exhaust gas of internal combustion engine.

\section{REFERENCES}

1. Conformity Test Certificate, 2019. Enggsol Engineering India, p. 1.

2. Danylyan A. 2019. The introduction of Electro-Hydraulic affect to reduce harmful emissions in the exhaust gases of marine diesel engines. V International Conference of European Academy of Sciences \& Sciences Research, Bonn, Germany, (April-May, 2019), 24-26.

3. Danylyan, A., Zalozh, V., Rudenko, M. 2017. Creation of new directions for reducing harmful emissions in the exhaust gases of internal combustion engines. Bulletin of Odessa National University, 2(51), 73-82.

4. Guidelines for the calculation of emissions of pollutants into the atmosphere, 1987. Ministry of the River Fleet of the RSFR, 2-18.

5. MARPOL 73/78, 2018. Annex 6, 3-178.

6. Materials of the meeting of the International Danube Commission on the implementation TFK, 2016. Budapest, 2-11.

7. Report on the research work on the implementation of TFK, 2018. Danube Institute NU "OMA", 2-30.

8. Test report on the ship "Kapitan Zhidkov", 2017. Institute of Ecology and energy conservation, Kiev, $2-54$.

9. Test report on the ship "Mechanic Senilov", 2018. Institute of Ecology and energy conservation, Kiev, $2-70$.

10. TFK Test Program, Danube Institute of NU "OMA", 2018, 2-12. 